\begin{tabular}{|c|c|c|c|c|c|c|}
\hline & \begin{tabular}{l|l|l|l} 
& $\mathbf{J}$ & $\mathbf{P}$ & $\mathbf{I}$ \\
\end{tabular} & $\begin{array}{lll}6 & 0 & \\
\end{array}$ & $\mathbf{R}$ & Dispatch: 30.4 .08 & Journal: JPI & CE: T.M. Prasath \\
\hline 2 & Journal Name & Manuscript No. & & Author Received: & No. of pages: 10 & PE: Radhika \\
\hline
\end{tabular}

\title{
Melatonin ameliorates calcium homeostasis in myocardial and ischemia-reperfusion injury in chronically hypoxic rats
}

\begin{abstract}
Chronic hypoxia $(\mathrm{CH})$ leads to the deterioration of myocardial functions with impaired calcium handling in the sarcoplasmic reticulum (SR), which may be mediated by oxidative stress. We hypothesized that administration of antioxidant melatonin would protect against cardiac and ischemia-reperfusion (I/R) injury by ameliorating SR calcium handling. Adult Sprague-Dawley rats that had received a daily injection of melatonin or vehicle were exposed to $10 \%$ oxygen for $4 \mathrm{wk}$. The heart of each rat was then dissected and perfused using a Langendorff apparatus. The ratio of heart-to-body weight, ventricular hypertrophy and hematocrit were increased in the hypoxic rats compared with the normoxic controls. Malondialdehyde levels were also increased in the heart of hypoxic rats and were lowered by the treatment of melatonin. The hearts were subjected to left coronary artery ischemia $(30 \mathrm{~min}$ ) followed by 120 -min reperfusion. Lactate dehydrogenase leakage before ischemia, during $\mathrm{I} / \mathrm{R}$ and infarct size of the isolated perfused hearts were significantly elevated in the vehicletreated hypoxic rats but not in the melatonin-treated rats. Spectroflurometric studies showed that resting calcium levels and I/R-induced calcium overload in the cardiomyocytes were more significantly altered in the hypoxic rats than the normoxic controls. Also, the hypoxic group had decreased levels of the SR calcium content and reduced amplitude and decay time of electrically induced calcium transients, indicating impaired contractility and SR calcium re-uptake. Moreover, there were reductions in protein expression of calcium handling proteins, markedly shown at the level of SR-Ca ${ }^{2+}$ ATPase (SERCA) in the heart of hypoxic rats. Melatonin treatment significantly mitigated the calcium handling in the hypoxic rats by preserving SERCA expression. The results suggest that melatonin is cardioprotective against $\mathrm{CH}$-induced myocardial injury by improving calcium handling in the SR of cardiomyocytes via an antioxidant mechanism.
\end{abstract}

\author{
H. M. Yeung, M. W. Hung and \\ M. L. Fung \\ Department of Physiology, University of Hong \\ Kong, Hong Kong SAR, China \\ Key words: antioxidant, calcium, \\ cardioprotection, chronic hypoxia, ischemia, \\ melatonin \\ Address reprint requests to M. L. Fung, Ph.D. \\ Department of Physiology, The University of \\ Hong Kong, 21 Sassoon Road, Pokfulam, \\ Hong Kong, China. \\ E-mail: fungml@ hkucc.hku.hk \\ Received December 12, 2007; \\ accepted April 16, 2008.
}

\section{Introduction}

Myocardial hypoxia can be caused by ischemic hypoxia with a local reduction of coronary blood flow and by systemic hypoxia with lowered levels of arterial oxygen. It is well accepted that myocardial injury is closely associated with the severity of ischemic hypoxia relevant to the clinical manifestation of ischemic heart disease. Yet myocardial injury, if any, caused by systemic hypoxia at moderate levels under chronic conditions is still controversial. This may relate to the fact that myocardial function is essentially normal in high-altitude natives, in subjects during ascent and sojourns at high altitudes, and in patients with chronic obstructive pulmonary disease (COPD). Many studies have showed that short-term hypoxia can confer cardioprotection against myocardial infarction, contractile dysfunction and ventricular arrhythmias [1-3]. However, hypoxia in the long term could have adverse effects on myocardial functions, particularly shown by the deterioration of calcium $\left(\mathrm{Ca}^{2+}\right)$ homeostasis in sarcoplasmic reticulum (SR) $[4,5]$ and by impaired Gs(alpha) and adenylyl cyclase intracellular signaling functions leading to altered myocardial responses to beta-adrenoceptor activation [6].

Recent studies have shown that overproduction of reactive-oxygen species (ROS) is a major mechanistic cause of myocardial injury during ischemia/hypoxia-reperfusion (I/R) [7-9]. Such a robust increase in cellular ROS levels could lead to opening of mitochondrial permeability transition pore $[10,11]$ and impaired intracellular $\mathrm{Ca}^{2+}$ homeostasis $[12,13]$. Hence, one rationale behind pharmacologically induced cardioprotection against $\mathrm{I} / \mathrm{R}$ injury was to lower the ROS level during the oxidative insult. However, it is not clear if this pharmacological strategy could be beneficial to myocardial functions under chronically hypoxic conditions.

It is well known that melatonin, as well as its metabolites are potent antioxidants $[14,15]$ and melatonin is a cardioprotective agent against $\mathrm{I} / \mathrm{R}$ injuries [16-22]. The 
mechanistic effect of melatonin on I/R-induced myocardial infarction is commonly attributed to its antioxidant properties and its ability to scavenge free radical species [23-25] while also stimulating the synthesis of antioxidant enzymes [26-28]. Although recent studies have documented the acute effects of melatonin against myocardial $\mathrm{I} / \mathrm{R}$ injury, currently there is a lack of information on the chronic effect of melatonin on myocardial functions in prolonged hypoxia $(\mathrm{CH})$. In this study, we examined the hypothesis that chronic administration of melatonin can alleviate $\mathrm{CH}$ induced myocardial injury in rats. Results suggested that the melatonin treatment could reduce the level of oxidative stress and mitigate SR-Ca ${ }^{2+}$ handling in the cardiomyocytes leading to improved myocardial functions in the hypoxic rats.

\section{Material and methods}

\section{Animals}

Animal care and experimental protocol for this study were approved by the Committee on the Use of Live Animals in Teaching and Research of The University of Hong Kong. The Laboratory Animal Unit of The University of Hong Kong is fully accredited by the Association for Assessment and Accreditation for Laboratory Animal Care (AAALAC International). Male Sprague-Dawley rats weighing about $70 \mathrm{~g}$ at age 28 days were randomly divided into normoxic and $\mathrm{CH}$ groups as reported previously [4-6]. While the normoxic controls were maintained in room air, $\mathrm{CH}$ rats were kept in a 300-L acrylic chamber for normobaric hypoxia in the same room and had free access to water and chow. The oxygen fraction inside the chamber was kept at $10 \pm 0.5 \%, 24 \mathrm{hr}$ per day. The desired oxygen content was established by a mixture of room air and nitrogen that was regulated and monitored by an oxygen analyzer (Vacumetrics Inc., CA, USA) [29]. The rats were exposed to hypoxia for 28 days and were immediately used in the experiments. The animal room was controlled at a constant temperature $\left(22 \pm 2{ }^{\circ} \mathrm{C}\right)$, humidity and light:dark cycle (lights on $07: 00$ 19:00).

\section{Drug preparation}

Melatonin (Sigma, St. Louis, MO, USA) solution was prepared fresh before injection by dissolving the indoleamine in absolute ethanol and further dilution with normal saline; the final concentration of ethanol was $2 \%$. As reported previously, melatonin in $10 \mathrm{mg} / \mathrm{kg}$ body weight [30-33] or vehicle ( $2 \%$ ethanol in normal saline) was administered intraperitoneally each day. The rats were taken out of the chamber for $30 \mathrm{~min}$ for the administration.

\section{Isolated perfused heart preparation}

Rats from normoxic and $\mathrm{CH}$ groups (both melatonin- and vehicle-treated groups) were decapitated and the hearts were quickly removed and placed in ice-cold KrebsHenseleit (K-H) perfusion buffer before being mounted on the Langendorff apparatus for perfusion at $37^{\circ} \mathrm{C}$ with K-H buffer at constant pressure $\left(100 \mathrm{~cm}\right.$ of $\left.\mathrm{H}_{2} \mathrm{O}\right)$ and equilibrated with $95 \%$ of $\mathrm{O}_{2} / 5 \% \mathrm{CO}_{2}$. The buffer contained (in $\mathrm{mm}$ ) $118.0 \mathrm{NaCl}, 4.7 \mathrm{KCl}, 1.25 \mathrm{CaCl}_{2}, 1.2 \mathrm{KH}_{2} \mathrm{PO}_{4}, 1.2$ $\mathrm{MgSO}_{4}, 25.0 \mathrm{NaHCO}_{3}$ and 11.0 glucose. All the hearts were subjected to regional ischemia described previously [34, 35]. Briefly, a snare was formed by placing a silk suture around the left coronary artery of rat heart. The snare was pulled in order to occlude the coronary artery to produce ischemia. Reperfusion was done by releasing the snare. In this present study, the isolated rat hearts were subjected to $30 \mathrm{~min}$ of ischemia followed by $120 \mathrm{~min}$ of reperfusion which induced myocardial injury.

\section{Measurement of the area of risk}

To determine the infarct size, the coronary artery was re-occluded at the end of reperfusion and the heart was perfused with $2.5 \%$ Evans blue to delineate the area of risk. The hearts were frozen at $-70^{\circ} \mathrm{C}$, cut into thin slices, which were perpendicular to the septum, from the apex to the base. Then incubated in sodium phosphate buffer containing $1 \%(\mathrm{w} / \mathrm{v}) \quad 2,3,5$-triphenyl-tetrazolium chloride for $10 \mathrm{~min}$ in order to visualize the unstained infarct region. The infarct and the risk zone areas were determined by planimetry with software Image/J from the National Institutes of Health (Bethesda, MD). The infarct size measured was expressed as a percentage of the risk zone.

\section{Determination of myocardial injury by lactate dehydrogenase (LDH) efflux}

The effluent from each isolated perfused rat heart was collected at $15 \mathrm{~min}$ before regional ischemia, 5th $\mathrm{min}$ of reperfusion and the $\mathrm{LDH}$ was assayed spectrophotometrically by using a kit purchased from Sigma-Aldrich (St. Louis, MO, USA). The LDH activity measured was expressed as units per liter.

\section{Measurement of lipid peroxidation}

The lipid peroxidation was determined by using a Bioxytech $^{\circledR}$ LPO-586 ${ }^{\mathrm{TM}}$ kit (OxisResearch, OR, USA). The reaction product was measured spectrophotometrically at $586 \mathrm{~nm}$. Standard curves were constructed with 1,1,3,3tetraethoxypropane as a standard. The level of malondialdehyde (MDA) in the heart is expressed as $\mu \mathrm{M}$, while the MDA concentration $(\mu \mathrm{M})$ in heart was normalized to wet tissue weight (mg) and expressed as $\mu \mathrm{M} / \mathrm{mg}$.

\section{Preparation of isolated ventricular myocytes}

Single ventricular myocytes were isolated from the normoxic and $\mathrm{CH}$ rats by using a collagenase method described previously $[35,36]$. After isolation, myocytes were allowed to stabilize for at least $30 \mathrm{~min}$ before any experiment.

\section{Measurement of $\left[\mathrm{Ca}^{2+}\right]_{\mathrm{i}}$}

A spectrofluorometric method with Fura-2/AM as a $\mathrm{Ca}^{2+}$ indicator was used during the measurement of $\left[\mathrm{Ca}^{2+}\right]_{\mathrm{i}}$. Ventricular myocytes from either normoxic or hypoxic rats were incubated with $5 \mu \mathrm{M}$ Fura-2/AM for $35 \mathrm{~min}$. 
Fluorescent signals obtained at $340 \mathrm{~nm}$ (F340) and $380 \mathrm{~nm}$ (F380) excitation wavelengths were recorded and stored in computer for data processing and analysis. The F340/F380 ratio was used to indicate cytosolic $\left[\mathrm{Ca}^{2+}\right]_{i}$ in the ventricular myocytes. During the measurement of electrically induced $\left[\mathrm{Ca}^{2+}\right]_{\mathrm{i}}$ transients $\left(\mathrm{E}\left[\mathrm{Ca}^{2+}\right]_{\mathrm{i}}\right)$, myocytes were electrically stimulated at $0.2 \mathrm{~Hz}$, whereas measurement of caffeine-induced $\left[\mathrm{Ca}^{2+}\right]_{\mathrm{i}}$ transients $\left(\mathrm{C}\left[\mathrm{Ca}^{2+}\right]_{\mathrm{i}}\right)$ were done by applying $10 \mathrm{~mm}$ caffeine directly to the ventricular myocytes. The amplitude of $\mathrm{E}\left[\mathrm{Ca}^{2+}\right]_{i}$ and $\mathrm{C}\left[\mathrm{Ca}^{2+}\right]_{i}$ were determined as the difference between the resting and the peak $\left[\mathrm{Ca}^{2+}\right]_{\mathrm{i}}$ levels; the time for $50 \%$ decay of the transients $\left(\mathrm{T}_{50}\right)$ was used to represent the decay of both transients. During the measurements, the isolated fura-2-loaded cardiomyocytes from each group were incubated for $10 \mathrm{~min}$ with non-glucose K-H solution containing $10 \mathrm{~mm}$ 2-deoxyD-glucose and $10 \mathrm{~mm}$ sodium dithionite to induce metabolic inhibition and anoxia (MI/A). Reperfusion (MI/A-R) was followed by incubating the myocytes with normal K-H solution for further $10 \mathrm{~min}$.

\section{Western blotting for SERCA, RyR and NCX}

Isolated cardiomyocytes from normoxic and hypoxic groups were collected after collagenase digestion from whole hearts. To detect the expression of SERCA2 and RyR, SR vesicles were obtained by following procedures. Briefly, myocytes were sonicated on ice in the extraction medium containing (in mM): 15 Tris, $10 \mathrm{NaHCO}_{3}, 5 \mathrm{NaN}_{3}$, 250 sucrose and 1 EDTA ( $\mathrm{pH} 7.3)$. The homogenate were centrifuged for $10 \mathrm{~min}$ at $1000 \mathrm{~g}$ to remove cellular debris. The supernatant was further centrifuged for $35 \mathrm{~min}$ at $20,000 \mathrm{~g}$. Then the pellet was re-suspended in a mixture of $0.6 \mathrm{M} \mathrm{KCl}$ and $0.03 \mathrm{M}$ histidine $(\mathrm{pH} 7.0)$ and centrifuged for $35 \mathrm{~min}$ at $20,000 \mathrm{~g}$. The final pellet was re-suspended in a mixture of $0.25 \mathrm{M}$ sucrose and $0.01 \mathrm{M}$ histidine $(\mathrm{pH} 7.3)$ and stored at $-70^{\circ} \mathrm{C}$. All solutions contained three proteases inhibitors: $1 \mathrm{mg} / \mathrm{mL}$ leupeptin, $1 \mathrm{mg} / \mathrm{mL}$ aprotinin and $1 \mathrm{~mm}$ phenylmethylsulfonyl fluoride (PMSF). For the measurement of NCX, purification of plasma membrane vesicles were carried out as described above. The pellet i.e. sarcolemma-enriched fraction was dissolved in the lysis buffer $(0.6 \mathrm{~m}$ sucrose and $10 \mathrm{~mm}$ imidazole- $\mathrm{HCl}, \mathrm{pH} 7.0)$ and stored at $-70^{\circ} \mathrm{C}$. The protein concentration of the samples was quantified by the Bio-Rad protein assay method by using bovine serum albumin (BSA) for the standard curve. Sample proteins $(20 \mu \mathrm{g} /$ lane $)$ were separated in SDS-polyacrylamide gel $(10 \%$ for SERCA and NCX; 6\% for RyR) and transferred electrophoretically to polyvinylidene difluoride membranes $(0.2 \mu \mathrm{m}$ pore size;

1Bio-Rad) at $4{ }^{\circ} \mathrm{C}$ in transfer buffer with glycine, Tris and $20 \%$ methanol with the Bio-Rad Trans-blot electrophoretic transfer system. After blocking with Tris-buffered saline (TBS; with Tris, $\mathrm{NaCl}$ and $0.2 \%$ Tween 20 ) containing $5 \%$ non-fat milk, the membranes were incubated overnight at $4^{\circ} \mathrm{C}$ with the goat anti-SERCA2a polyclonal antibody (1:400 dilution; Santa Cruz Biotechnology, Santa Cruz, CA, USA), mouse anti-RyR2 monoclonal antibody (1:3330 dilution; Affinity BioReagent, Golden, CO, USA), mouse anti-NCX1 monoclonal antibody (1:500 dilution; Abcam, Cambridge, UK) and mouse anti- $\beta$-actin monoclondal antibody (1:5000 dilution; Santa Cruz Biotechnology). The second antibody for both protein determinations was anti-goat or anti-mouse antibody conjugated to horseradish peroxidase (1:2000 dilution; Dakocytomation, Denmark $\mathrm{A} / \mathrm{S})$ in 5\% non-fat milk TBS for $1 \mathrm{hr}$ at room temperature. The protein bands of SERCA, RyR and NCX were detected by the chemiluminescence method (ECL 2Western blotting detection; Amersham Biosciences).

\section{Statistical analysis}

Values are expressed as means \pm S.E.M. One-way ANOVA (Turkey's multiple comparison test) was used to determine the differences among the multiple groups. The significance level was set at $P<0.05$.

\section{Results}

As shown in Fig. 1, the ratio of heart-to-body weight was increased in the $\mathrm{CH}$ rats (vehicle- and melatonin-treated
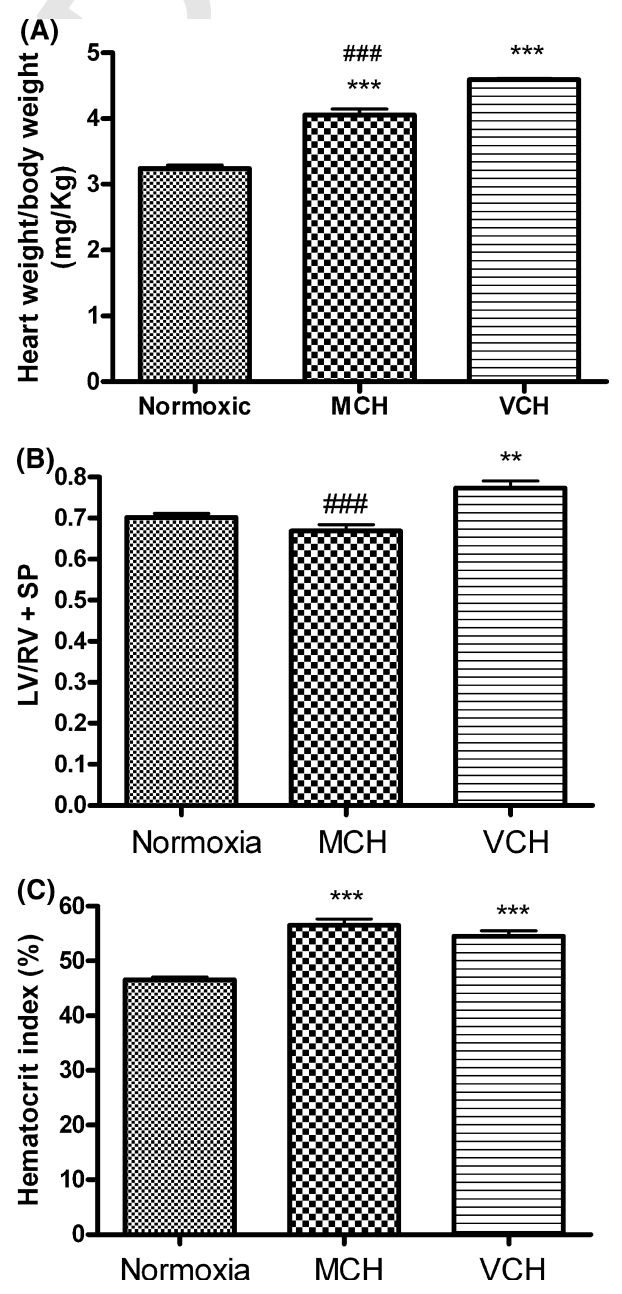

3Fig. 1. Ratios of (A) heart weight to body weight, (B) left ventricle to right ventricle and septum, (C) hematocrit in normoxic control, vehicle-treated $(\mathrm{VCH})$ and melatonin-treated $(\mathrm{MCH})$ hypoxic rats. Values are means \pm S.E.M., $\mathrm{n}=6$ rats each group. ${ }^{*} P<0.05$ and $* * * P<0.001$ versus normoxic group and ${ }^{\# \#} P<0.001$ versus VCH group. RV, right ventricle; LV, left ventricle; SP, septum. 


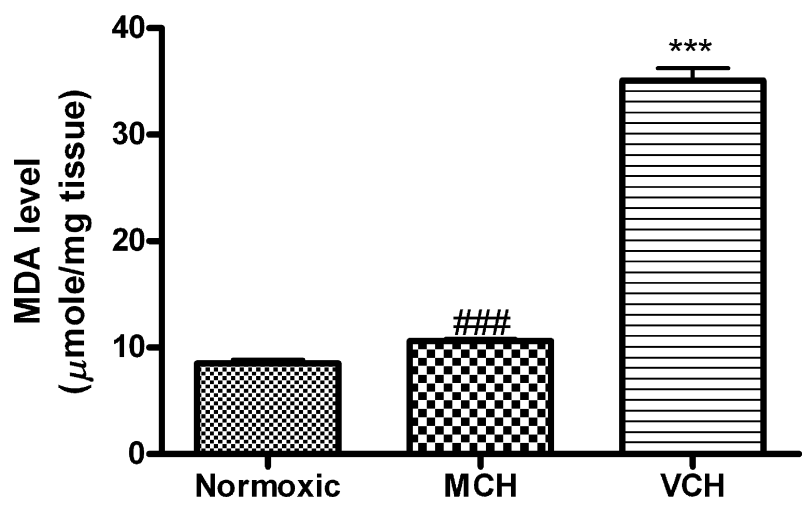

Fig. 2. Levels of MDA in the rat heart in normoxic control, vehicletreated $(\mathrm{VCH})$ and melatonin-treated $(\mathrm{MCH})$ hypoxic rats. Values are means \pm S.E.M., $\mathrm{n}=6$ rats each group. ${ }^{* * *} P<0.001$ versus normoxic group and ${ }^{\# \# \#} P<0.001$ versus VCH group.
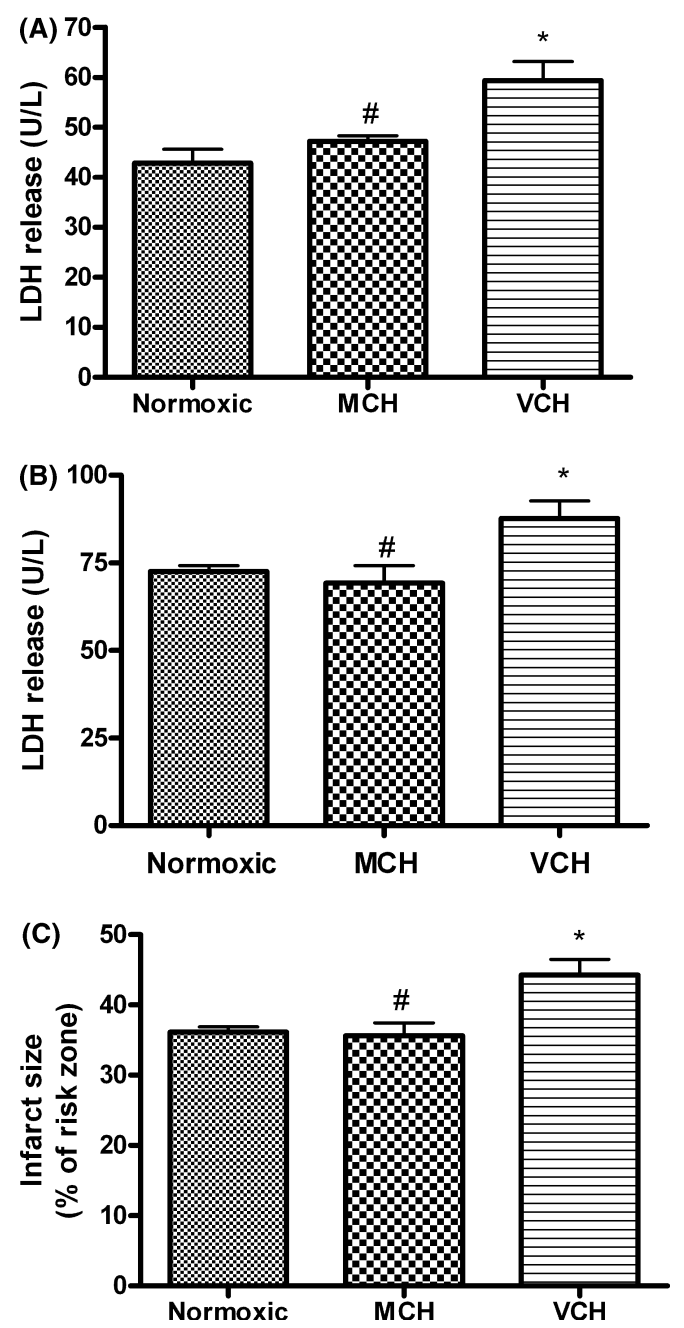

Fig. 3. Levels of LDH release (A) before 30-min ischemia, (B) during 5-min of reperfusion and (C) the infarct size in rat hearts subjected to 30-min ischemia followed by 120 -min reperfusion. Values are means \pm S.E.M., $\mathrm{n}=6$ rats in each normoxic control, vehicle-treated $(\mathrm{VCH})$ and melatonin-treated $(\mathrm{MCH})$ hypoxic group. ${ }^{*} P<0.05$ versus normoxic group and ${ }^{\#} P<0.05 \mathrm{VCH}$ group. groups were, respectively, $143.8 \%$ and $125 \%$ of the normoxic control). The ratio of left ventricular weight to the right ventricle and septum in the vehicle-treated hypoxic rat was increased by $10.1 \%$ of the normoxic control, but was not different between the melatonin-treated hypoxic rat and the normoxic control (Fig. 1B). Hematocrit was increased by $17.0 \%$ and $21.2 \%$, respectively, in the vehicleand melatonin-treated rats, comparing with the normoxic control (Fig. 1C).

Fig. 2 shows the MDA level in the cardiac tissue, representing the level of lipid peroxidation under oxidative stress. The MDA level significantly increased in the vehicle group, which was $313 \%$ of the normoxic control, but the increase was much less at $25 \%$ in the melatonin group.

Before ischemia, the resting level of the $\mathrm{LDH}$ release from the perfused heart of the vehicle-treated hypoxic rats was significantly elevated by $38.6 \%$ of the normoxic control (Fig. 3A). There were no differences in the resting $\mathrm{LDH}$ release between the melatonin-treated group and the normoxic control, suggesting that melatonin reduced the $\mathrm{CH}$-induced myocardial injury. In addition, the $\mathrm{LDH}$ release during 5 min reperfusion after ischemia was markedly increased in the vehicle group $(127 \%$ of the normoxic control) but not in the melatonin-treated group (105\% of the normoxic control, Fig. 3B). Moreover, the infarct size of the hearts in the melatonin-treated hypoxic rat (101\% of the normoxic control) was significantly less than that of the vehicle group (124\% of the normoxic control, Fig. 3C).
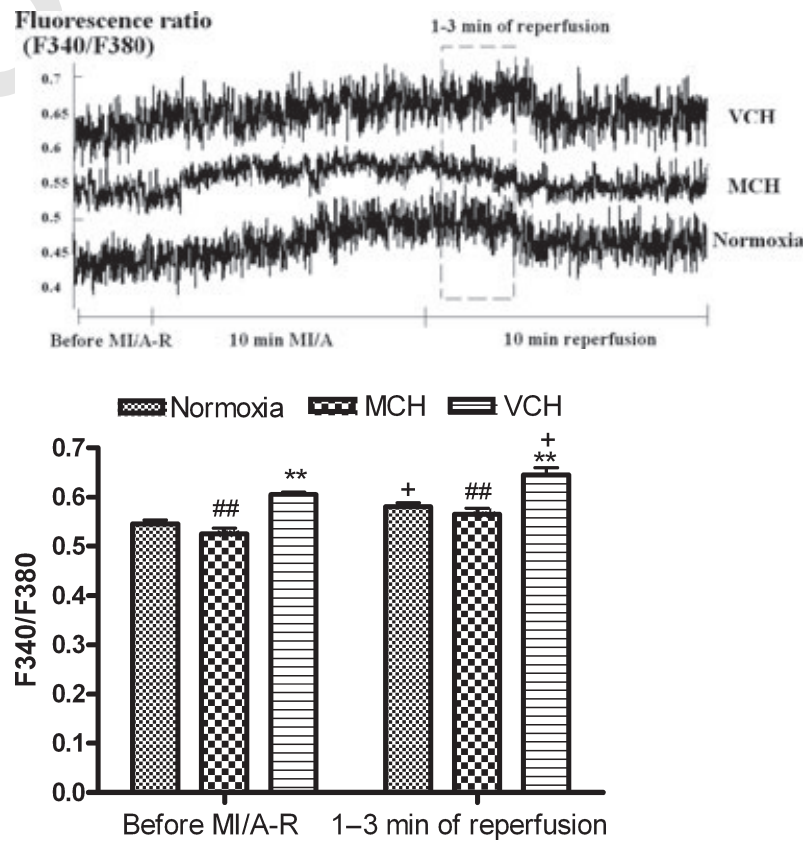

4Fig. 4. Levels of the intracellular calcium shown by fluorescence ratio $(\mathrm{F} 340 / \mathrm{F} 380)$ recorded from the isolated ventricular myocyte before and during 10-min metabolic inhibition and anoxia (MI/A) and 10-min reperfusion (MI/A-R). Values are means \pm S.E.M., $\mathrm{n}=3-4$ myocytes from three to four rats in each normoxic control, vehicle-treated $(\mathrm{VCH})$ and melatonin-treated $(\mathrm{MCH})$ hypoxic group. $* * P<0.01$ versus corresponding normoxic group; ${ }^{\# \#} P<0.01$ versus corresponding VCH group; ${ }^{+} P<0.05$ versus corresponding group before MI/A-R. 


\section{Fluorescence ratio (F340/F380)}

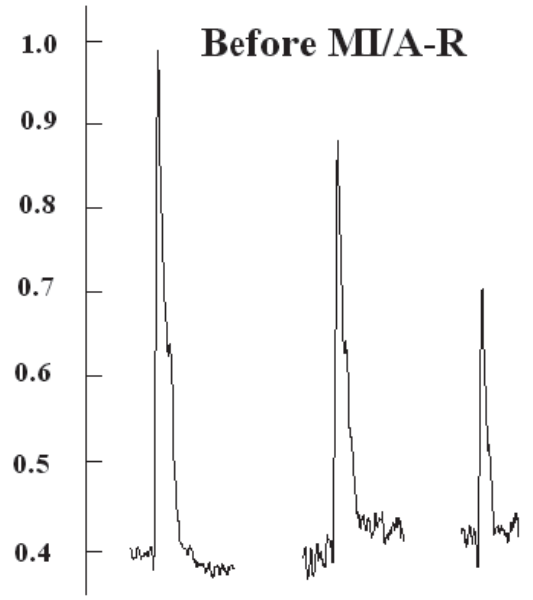

Normoxia MCH VCH
After MI/A-R

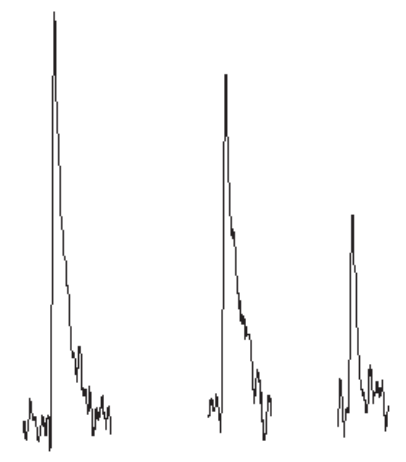

Normoxia MCH VCH
Fig. 5. (A) Amplitude and (B) decay time of caffeine-induced calcium transients in the cardiomyocyte before and during 10 -min $\mathrm{MI} / \mathrm{A}-\mathrm{R}$. Values are means \pm S.E.M., $\mathrm{n}=3-4$ myocytes from three to four rats in each normoxic control, vehicle-treated $(\mathrm{VCH})$ and melatonin-treated $(\mathrm{MCH})$ hypoxic group. $* P<0.05$, $* * P<0.01$ versus corresponding normoxic group; ${ }^{\#} P<0.05$ versus corresponding $\mathrm{VCH}$ group; ${ }^{+} P<0.05$ versus corresponding group before MI/A-R.
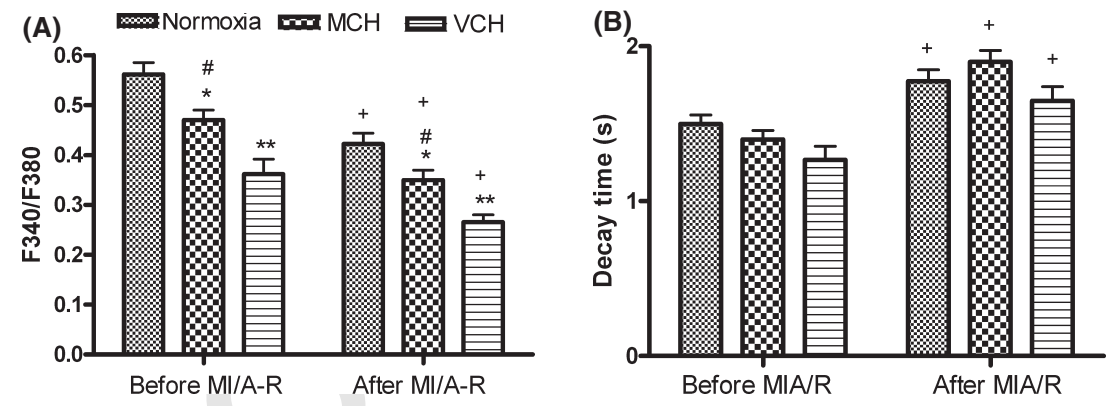

Before ischemia, the resting level of cytosolic calcium in isolated cardiomyocytes was higher in the hypoxic rats treated with vehicle than those of the melatonin-treated rats and the normoxic control (Fig. 4). Following $10 \mathrm{~min} \mathrm{MI/}$ A-R, the calcium overloading was worsened in the vehicle group ( $110 \%$ of the resting level), but was significantly less in the melatonin group (106\% of the resting level), compared with that of the normoxic control $(107 \%$ of the resting level).

The amplitude of caffeine-induced $\left[\mathrm{Ca}^{2+}\right]_{\mathrm{i}}\left(\mathrm{C}\left[\mathrm{Ca}^{2+}\right]_{\mathrm{i}}\right)$ reflects the $\mathrm{Ca}^{2+}$ content in the $\mathrm{SR}$ of the cardiomyocytes $[37,38]$. Before ischemia, the $\mathrm{C}\left[\mathrm{Ca}^{2+}\right]_{\mathrm{i}}$ amplitude was significantly lowered in the vehicle-treated hypoxic rats by $36 \%$ of the normoxic control (Fig. 5A). Yet, the reduced $\mathrm{SR}-\mathrm{Ca}^{2+}$ content was much less in the melatonin-treated rats, which was by $16 \%$ of the normoxic control. Following MI/A-R, the amplitudes were decreased further by $25 \%$ and $28 \%$ of the levels before MI/A-R, respectively in the normoxic control and vehicle-treated hypoxic rats. However, the decrease was less in the hypoxic rats treated with melatonin $(23 \%$ of the level before $\mathrm{MI} / \mathrm{A}-\mathrm{R})$, reflecting that $\mathrm{SR}-\mathrm{Ca}^{2+}$ content was better maintenance in the cardiomyocyte of $\mathrm{CH}$ rats with the melatonin treatment. Furthermore, the values of $\mathrm{T}_{50}$ of $\mathrm{C}\left[\mathrm{Ca}^{2+}\right]_{\mathrm{i}}$ (Fig. 5B) which mainly reflects sarcolemmal NCX activity during caffeine-induced RyR release of $\mathrm{Ca}^{2+}$ from SR [38, 39], were not different between the hypoxic rats and normoxic control before ischemia. The $\mathrm{T}_{50}$ values were significantly increased in all groups following $\mathrm{M}$ I/A-R but the increases were not different among the hypoxic rats and the normoxic control.

The amplitude of electrically induced $\left[\mathrm{Ca}^{2+}\right]_{\mathrm{i}}$ transients $\left(\mathrm{E}\left[\mathrm{Ca}^{2+}\right]_{\mathrm{i}}\right)$ reflects the $\mathrm{Ca}^{2+}$ release during excitationcontraction (E-C) coupling and directly correlates with shortening in rat cardiomyocytes [4, 40]. Before ischemia, the amplitude of $\mathrm{E}\left[\mathrm{Ca}^{2+}\right]_{i}$ was significantly lowered in the vehicle-treated hypoxic rats by $43.3 \%$ of the normoxic control (Fig. 6A). The lowered $\mathrm{E}\left[\mathrm{Ca}^{2+}\right]_{\mathrm{i}}$ level was much less in the hypoxic rats treated with melatonin, which was $20.0 \%$ of the normoxic control. The values of the amplitudes in all rat groups were significantly reduced during 13 min of ischemia-reperfusion with elevated ROS levels [41]. The amplitude of the $\mathrm{E}\left[\mathrm{Ca}^{2+}\right]_{\mathrm{i}}$ in the melatonin-treated rats was significantly greater than that of vehicle group. In addition, before ischemia the decay time $\left(\mathrm{T}_{50}\right)$ of $\mathrm{E}\left[\mathrm{Ca}^{2+}\right]_{\mathrm{i}}$ (Fig. 6B) which represents mainly the $\mathrm{Ca}^{2+}$ reuptake to SR via SERCA $\left(>90 \% \mathrm{Ca}^{2+}\right.$ in cytoplasm) and partly the extrusion to extracellular space by NCX [42, 43], was longer in the hypoxic rats than that of the normoxic group (by $37 \%$ and $23 \%$, respectively, in vehicle- and melatonintreated rats). During MI/A-R, the values were markedly prolonged in the normoxic control $(121 \%$ of that before $\mathrm{MI} / \mathrm{A}-\mathrm{R})$. However, the increase in $\mathrm{T}_{50}$ value was significantly less in the melatonin-treated rats $(13 \%$ of that before $\mathrm{MI} / \mathrm{A}-\mathrm{R})$ than that of the hypoxic rats treated with vehicle ( $23 \%$ of that before MI/A-R). Moreover, the time to peak of $\mathrm{E}\left[\mathrm{Ca}^{2+}\right]_{\mathrm{i}}$ (Fig. 6C) which indicates the speed of $\mathrm{Ca}^{2+}$ release via RyR of SR [6], was not different between the 
Tluorescence ratio(F340/F380)

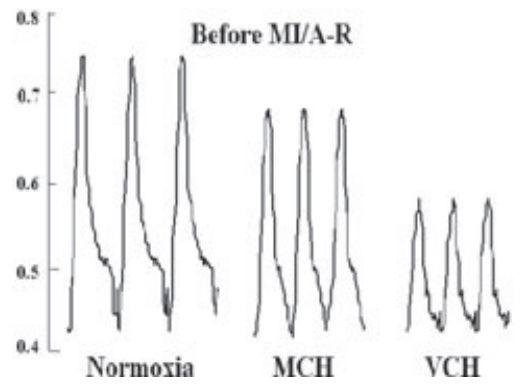

MCH
YCH
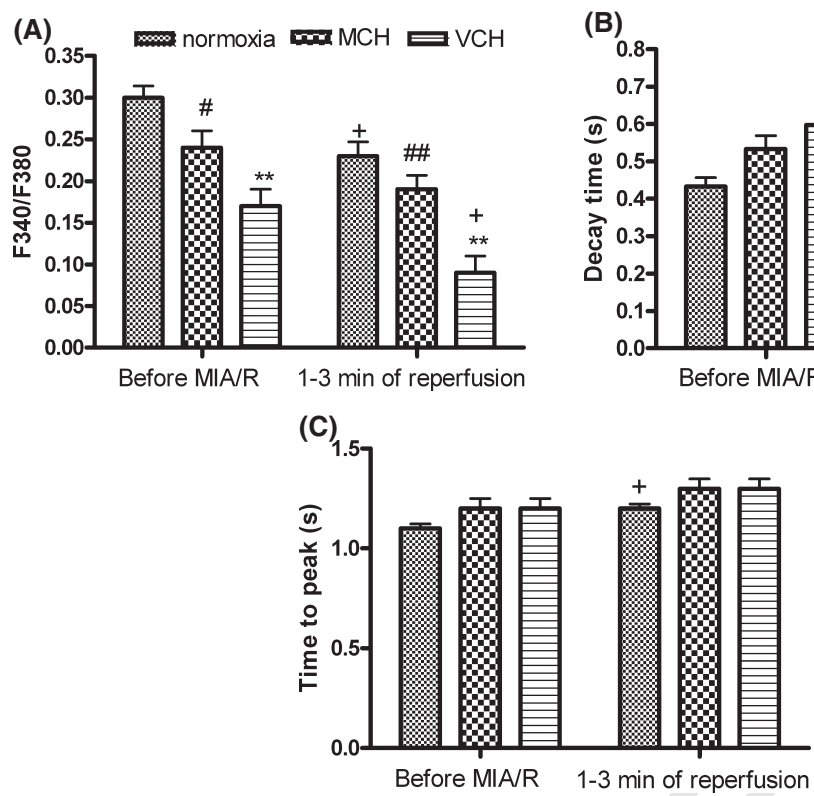

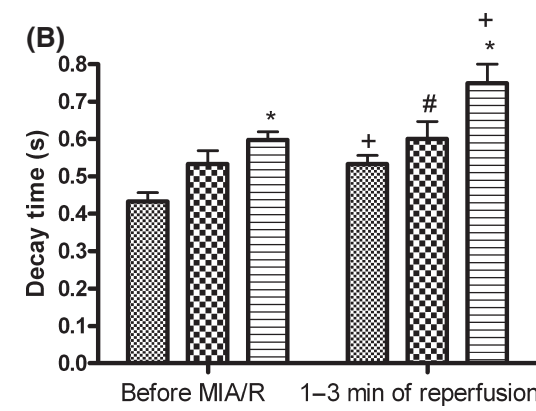

$1-3 \mathrm{~min}$ of reperfusion

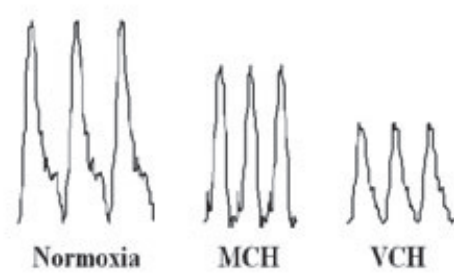

Fig. 6. (A) Amplitude, (B) decay time and (C) time-to-peak of electrically induced calcium transients in the cardiomyocyte before and during 10-min MI/A-R. Values are means \pm S.E.M., $\mathrm{n}=3-4$ myocytes from three to four rats in each normoxic control, vehicle-treated (VCH) and melatonin-treated $(\mathrm{MCH})$ hypoxic group. ${ }^{*} P<0.05, \quad * * P<0.01$ versus corresponding normoxic group; ${ }^{\#} P<0.05$ and ${ }^{\# \#} P<0.01$ versus corresponding VCH group; ${ }^{+} P<0.05$ versus corresponding group before MI/A-R. hypoxic and normoxic groups before MI/A. During MI/ A-R, the value was markedly increased in the normoxic group ( $9 \%$ of the level before MI/A-R) but the increase was not different from the melatonin-treated hypoxic rats.

The cardiac SERCA2a expression (Fig. 7A) was sharply decreased in the vehicle-treated hypoxic rats by $53 \%$ of the normoxic control. The reduced expression was significantly less in the hypoxic rats treated with melatonin, which was by $18.8 \%$ of the normoxic control. Yet, levels of the protein expression of $\mathrm{Na}^{+} / \mathrm{Ca}^{2+}$ exchanger (NCX1) (Fig. 7B) and ryanodine receptor (RyR2) (Fig. 7C) in $\mathrm{CH}$ rat hearts were not different from those of the normoxic control.

\section{Discussion}

The major finding of this study is that melatonin markedly lowered the levels of oxidative stress, $\left[\mathrm{Ca}^{2+}\right]_{\mathrm{i}}$ overload and $\mathrm{I} / \mathrm{R}$ injury in the myocardium by ameliorating SERCA expression and function for the calcium handling in the SR of cardiomyocytes in $\mathrm{CH}$ rats. Results support the contention that antioxidant melatonin and/or its metabolites are cardioprotective against $\mathrm{CH}$-induced myocardial injury.

In consistent to our previous findings [4-6], the $\mathrm{CH}$ heart was hypertrophied with diminished $\left[\mathrm{Ca}^{2+}\right]_{\mathrm{i}}$ handling, which imitates the pathogenic development of heart failure. In this study, we found that melatonin treatment was significant in reducing the myocardial injury in $\mathrm{CH}$ rats. Hence, levels of the cardiac hypertrophy and resting LDH release were markedly lowered by melatonin treatment in the hypoxic rats. This is likely to be explained by the fact that the level of oxidative stress shown by the MDA level in the cardiac tissue of the melatonin-treated rat was not different from the normoxic control, strongly suggesting a free radical scavenging mechanism mediated by the antioxidant property of melatonin.

Previous studies have reported that melatonin is a cardioprotective agent against myocardial and I/R injuries [16-20, 44]. Multiple mechanisms could explain the antioxidant property of melatonin, including by scavenging oxygenbased free radicals directly [15, 45-49] or indirectly by stimulating antioxidant enzymes [50, 51] and increasing mitochondrial oxidative phosphorylation to lower free radical generations $[45,52-55]$. We found that melatonin not only reduced MDA levels, but also lowered the LDH release and infarct size induced by $\mathrm{I} / \mathrm{R}$ in the $\mathrm{CH}$ rat heart. This observation was anticipated because melatonin treatment lessened the oxidative stress in the $\mathrm{CH}$ heart and this might improve cardiac tolerance against the oxidative injury induced by ROS overproduction during I/R [56-58]. These results support the idea that the administration of melatonin could be a preventive treatment for the worsening myocardial function and injury under $\mathrm{CH}$ conditions. 

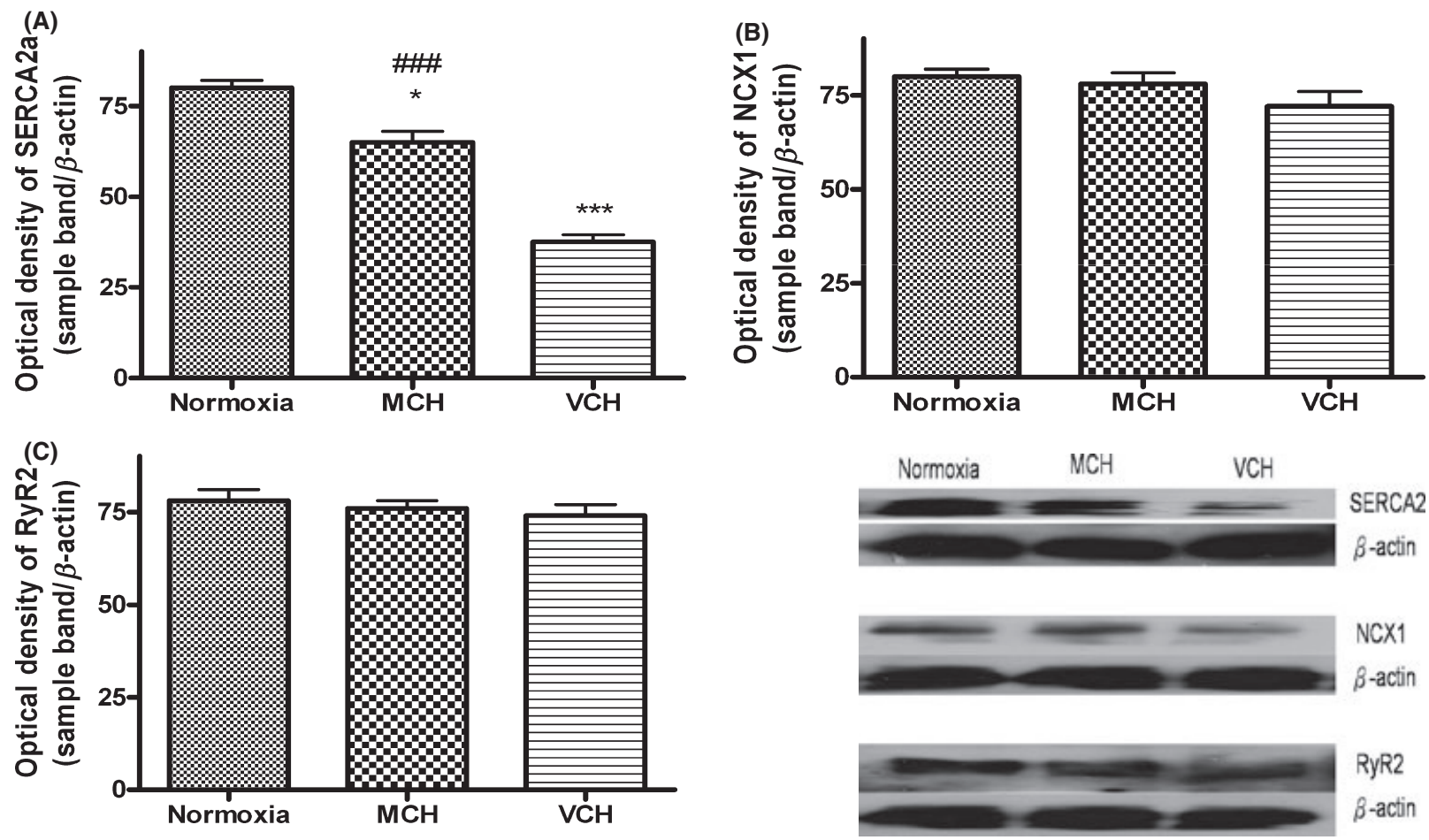

Fig. 7. Levels of the protein expression of (A) SERCA2, (B) NCX1 and (C) RyR2 in the rat heart of normoxic control, vehicle-treated $(\mathrm{VCH})$ and melatonin-treated $(\mathrm{MCH})$ hypoxic rats. Values are means \pm S.E.M., $\mathrm{n}=6$ rats in each group. ${ }^{*} P<0.05$ and ${ }^{* * *} P<0.001$ versus normoxic group and ${ }^{\# \#} P<0.001$ versus $\mathrm{VCH}$ group.

For the cellular and molecular alterations in the pathogenesis of a failing heart, it is well known that $\mathrm{Ca}^{2+}$ plays an important role in maintaining cardiac functions. The SR and sarcolemma of the cardiomyocytes are major components of normal $\mathrm{Ca}^{2+}$ homeostasis in the heart [59]. When the depolarization of the action potential activates L-type $\mathrm{Ca}^{2+}$ channels, $\mathrm{Ca}^{2+}$ influx occurs to increase $\left[\mathrm{Ca}^{2+}\right]_{\mathrm{i}}$ levels. A small rise in $\left[\mathrm{Ca}^{2+}\right]_{i}$ triggers $\mathrm{Ca}^{2+}$ release from SR via $\mathrm{RyR}$, by the process known as $\mathrm{Ca}^{2+}$-induced $\mathrm{Ca}^{2+}$ release [60]. During relaxation, most of the $\mathrm{Ca}^{2+}$ released is sequestered by the SR via SERCA and partly extruded out of the cell via the sarcolemmal sodium calcium exchange (NCX). It has been shown that I/R impairs SR function by depressing phosphorylation of $\mathrm{SR} \mathrm{Ca}^{2+}$ handling proteins [61-63] and results in impaired $\mathrm{Ca}^{2+}$ homeostasis leading to $\left[\mathrm{Ca}^{2+}\right]_{\mathrm{i}}$ overload and damaging myocardial contractility in rat cardiomyocytes [64-66]. In agreement with our previous findings [6], $\mathrm{CH}$ significantly lowered the amplitudes of caffeine- and electrically induced $\left[\mathrm{Ca}^{2+}\right]_{\mathrm{i}}$, suggesting decreased SR $\mathrm{Ca}^{2+}$ content and contractility in $\mathrm{CH}$ rat cardiomyocytes.

Moreover, we demonstrated that during $\mathrm{MI} / \mathrm{A}-\mathrm{R}$, the impaired $\mathrm{Ca}^{2+}$ homeostasis in $\mathrm{CH}$ rat cardiomyocytes was more severe with elevated $\left[\mathrm{Ca}^{2+}\right]_{\mathrm{i}}$ overloading level and prolonged decay time $\left(\mathrm{T}_{50}\right)$ of $\mathrm{E}\left[\mathrm{Ca}^{2+}\right]_{\mathrm{i}}$, indicating deterioration of SR-Ca ${ }^{2+}$ re-uptake in the $\mathrm{CH}$ rat cardiomyocyte. Thus, the alterations in the SR-Ca ${ }^{2+}$ handling and $\mathrm{Ca}^{2+}$ homeostasis underlying the $\mathrm{CH}$-induced myocardial injury were in parallel to those induced by $\mathrm{I} / \mathrm{R}$, but rather developed in a progressive manner under $\mathrm{CH}$ conditions. Importantly, melatonin preserved the $\mathrm{SR}-\mathrm{Ca}^{2+}$ content and improved contractility in the $\mathrm{CH}$ rat cardiomyocyte. Furthermore, the protective effect of melatonin was also effective against the additional oxidative insult imposed by MI/A-R, which are essential to the increased myocardial tolerance against $\mathrm{I} / \mathrm{R}$ injury. This is in consistent with findings in previous studies suggesting that impaired myocardial and calcium handing functions are improved by the melatonin treatment [16-20,67].

To address whether alterations in the expression of $\mathrm{Ca}^{2+}$ handling proteins of SR and sarcolemma may account for the ameliorated $\mathrm{Ca}^{2+}$ homeostasis in the $\mathrm{CH}$ rat cardiomyocytes, we examined the protein expression of the SERCA, RyR and NCX. Our results showed that the protein expression of SERCA, but not RyR nor NCX, was significantly attenuated in the $\mathrm{CH}$ rat heart, supporting that lowered SR $\mathrm{Ca}^{2+}$ re-uptake causes the decreased SR-Ca ${ }^{2+}$ content and impaired $\mathrm{Ca}^{2+}$ homeostasis. This downregulation of the SERCA expression was not observed in the $\mathrm{CH}$ rats treated with melatonin, showing that the mechanistic effect on the ameliorated $\mathrm{SR}-\mathrm{Ca}^{2+}$ re-uptake and $\mathrm{Ca}^{2+}$ homeostasis could be mediated by a transcriptional regulation of the SERCA expression. Yet, the involvement of antioxidant effect of melatonin in the mechanistic detail of the SERCA regulation awaits further investigation.

In conclusion, we have shown that melatonin was cardioprotective against $\mathrm{CH}$-induced myocardial injury. Numerous other studies have also documented melatonin's cardioprotective actions under a variety of different situations [68]. Based on current findings, we proposed that the administration of melatonin could be a preventive approach to alleviate the oxidative stress in the heart under 
$\mathrm{CH}$ conditions, which is a major pathogenic cause of the alterations in myocardial function leading to subsequent injury and lowered tolerance to $\mathrm{I} / \mathrm{R}$ injury. The fact that chronic melatonin treatment mitigates the SR-Ca ${ }^{2+}$ handling and $\mathrm{Ca}^{2+}$ homeostasis in the cardiomyocyte under $\mathrm{CH}$ conditions, addresses the cellular mechanism for the cardioprotective effect of melatonin. In addition, the regulation of SERCA expression is involved in the mechanistic effect of melatonin on the improved myocardial function in $\mathrm{CH}$, thus, functionally important for maintaining the replenishment of SR-Ca ${ }^{2+}$ content and preventing the $\left[\mathrm{Ca}^{2+}\right]_{\mathrm{i}}$ overload. This provides a cellular basis for the better maintenance of $\mathrm{Ca}^{2+}$ homeostasis and contractility in cardiomyocytes under $\mathrm{CH}$ conditions and also the tolerance to $\mathrm{I} / \mathrm{R}$-induced myocardial injuries.

\section{Acknowledgments}

We thank Mr. W. B. Wong for the technical assistance. This study was supported by research grants from Research Grants Council, HKSAR, and the University Research Council of The University of Hong Kong.

\section{References}

1. Ostadal B, Kolar F. Cardiac adaptation to chronic highaltitude hypoxia: beneficial and adverse effects. Respir Physiol Neurobiol 2007; 158:224-236.

2. Kolar F, Ostadal B. Molecular mechanisms of cardiac protection by adaptation to chronic hypoxia. Physiol Res 2004; 53(Suppl. 1):S3-S13.

3. Kong X, Tweddell JS, Gross GJ et al. Sarcolemmal and mitochondrial $\mathrm{K}(\mathrm{atp})$ channels mediate cardioprotection in chronically hypoxic hearts. J Mol Cell Cardiol 2001; 33:10411045.

4. PeI JM, Yu XC, Fung ML et al. Impaired G(s)alpha and adenylyl cyclase cause beta-adrenoceptor desensitization in chronically hypoxic rat hearts. Am J Physiol Cell Physiol 2000; 279:C1455-C1463.

5. Shan J, Yu XC, Fung ML et al. Attenuated "cross talk" between kappa-opioid receptors and beta-adrenoceptors in the heart of chronically hypoxic rats. Pflugers Arch 2002; 444:126132.

6. Pei JM, Kravtsov GM, Wu S et al. Calcium homeostasis in rat cardiomyocytes during chronic hypoxia: a time course study. Am J Physiol Cell Physiol 2003; 285:C1420-C1428.

7. Duilio C, Ambrosio G, Kuppusamy $P$ et al. Neutrophils are primary source of $\mathrm{O}_{2}$ radicals during reperfusion after prolonged myocardial ischemia. Am J Physiol Heart Circ Physiol 2001; 280:H2649-H2657.

8. Kevin LG, Camara AK, Riess ML et al. Ischemic preconditioning alters real-time measure of $\mathrm{O}_{2}$ radicals in intact hearts with ischemia and reperfusion. Am J Physiol Heart Circ Physiol 2003; 284:H566-H574.

9. Zweier JL, Wang P, Kuppusamy P. Direct measurement of nitric oxide generation in the ischemic heart using electron paramagnetic resonance spectroscopy. J Biol Chem 1995; 270:304-307.

10. Halestrap AP, Clarke SJ, Javadov SA. Mitochondrial permeability transition pore opening during myocardial reperfusion - a target for cardioprotection. Cardiovasc Res 2004; 61:372-385.
11. Juhaszova M, Zorov DB, Kim SH et al. Glycogen synthase kinase-3beta mediates convergence of protection signaling to inhibit the mitochondrial permeability transition pore. J Clin Invest 2004; 113:1535-1549.

12. Lounsbury KM, Hu Q, Ziegelstein RC. Calcium signaling and oxidant stress in the vasculature. Free Radic Biol Med 2000; 28:1362-1369.

13. WAYPa GB, MARKS JD, MACK MM et al. Mitochondrial reactive oxygen species trigger calcium increases during hypoxia in pulmonary arterial myocytes. Circ Res 2002; 91: 719-726.

14. Rosen J, Than NN, Koch D et al. Interactions of melatonin and its metabolites with the ABTS cation radical: extension of the radical scavenger cascade and formation of a novel class of oxidation products, C2-substituted 3-indolinones. J Pineal Res 2006; 41:374-381.

15. Tan DX, Manchester LC, Terron MP et al. One molecule, many derivatives: a never-ending interaction of melatonin with reactive oxygen and nitrogen species? J Pineal Res 2007; 42:28-42.

16. Lee YM, Chen HR, Hsiao G et al. Protective effects of melatonin on myocardial ischemia/reperfusion injury in vivo. J Pineal Res 2002; 33:72-80.

17. TAN DX, MANChester LC, Reiter RJ et al. Ischemia/reperfusion-induced arrhythmias in the isolated rat heart: prevention by melatonin. J Pineal Res 1998; 25:184-191.

18. Szarszoi O, Asemu G, VaneceK J et al. Effects of melatonin on ischemia and reperfusion injury of the rat heart. Cardiovasc Drugs Ther 2001; 15:251-257.

19. Sahna E, ACET A, Ozer MK et al. Myocardial ischemiareperfusion in rats: reduction of infarct size by either supplemental physiological or pharmacological doses of melatonin. J Pineal Res 2002; 33:234-238.

20. Sahna E, Olmez E, Acet A. Effects of physiological and pharmacological concentrations of melatonin on ischemiareperfusion arrhythmias in rats: can the incidence of sudden cardiac death be reduced? J Pineal Res 2002; 32:194198.

21. Ressmeyer AR, Mayo JC, Zelosko V et al. Antioxidant properties of the melatonin metabolite N1-acetyl-5-methoxykynuramine (AMK): scavenging of free radicals and prevention of protein destruction. Redox Rep 2003; 8:205-213.

22. Guenther AL, Schmidt SI, LaAtsch H et al. Reactions of the melatonin metabolite AMK (N1-acetyl-5-methoxykynuramine) with reactive nitrogen species: formation of novel compounds, 3-acetamidomethyl-6-methoxycinnolinone and 3-nitro-AMK. J Pineal Res 2005; 39:251-260.

23. Reiter RJ, Tan DX, Manchester LC et al. Biochemical reactivity of melatonin with reactive oxygen and nitrogen species: a review of the evidence. Cell Biochem Biophys 2001; 34:237-256.

24. TAN DX, Reiter RJ, Manchester LC et al. Chemical and physical properties and potential mechanisms: melatonin as a broad spectrum antioxidant and free radical scavenger. Curr Top Med Chem 2002; 2:181-197.

25. Allegra M, Reiter RJ, Tan DX et al. The chemistry of melatonin's interaction with reactive species. J Pineal Res 2003; 34: $1-10$.

26. Antolin I, Rodriguez C, Sainz RM et al. Neurohormone melatonin prevents cell damage: effect on gene expression for antioxidant enzymes. FASEB J 1996; 10:882-890.

27. Rodriguez C, Mayo JC, Sainz RM et al. Regulation of antioxidant enzymes: a significant role for melatonin. J Pineal Res 2004; 36:1-9. 
28. Maldonado MD, Murillo-Cabezas F, Terron MP et al. The potential of melatonin in reducing morbidity-mortality after craniocerebral trauma. J Pineal Res 2007; 42:1-11.

29. TJong YW, Chen Y, Liong EC et al. Chronic hypoxia modulates the function and expression of melatonin receptors in the rat carotid body. J Pineal Res 2006; 40:125134.

30. Kazez A, Demirbag M, Ustundag B et al. The role of melatonin in prevention of intestinal ischemia-reperfusion injury in rats. J Pediatr Surg 2000; 35:1444-1448.

31. Eskiocak S, Tutunculer F, Basaran UN et al. The effect of melatonin on protein oxidation and nitric oxide in the brain tissue of hypoxic neonatal rats. Brain Dev 2007; 29:19-24.

32. Hung MW, Tipoe GL, Poon AM et al. Protective effect of melatonin against hippocampal injury of rats with intermittent hypoxia. J Pineal Res 2008; 44:214-221.

33. TJong YW, Li MF, Hung MW et al. Melatonin ameliorates hippocampal nitric oxide production and large conductance calcium-activated potassium channel activity in chronic intermittent hypoxia. J Pineal Res 2008; 44:234-243.

34. CAO CM, XIA Q, GAO Q et al. Calcium-activated potassium channel triggers cardioprotection of ischemic preconditioning. J Pharmacol Exp Ther 2005; 312:644-650.

35. Yeung HM, Kravtsov GM, NG KM et al. Chronic intermittent hypoxia alters $\mathrm{Ca}^{2+}$ handling in rat cardiomyocytes by augmented $\mathrm{Na}^{+} / \mathrm{Ca}^{2+}$ exchange and ryanodine receptor activities in ischemia-reperfusion. Am J Physiol Cell Physiol 2007; 292:C2046-C2056.

36. WU S, LI HY, WONG TM. Cardioprotection of preconditioning by metabolic inhibition in the rat ventricular myocyte. Involvement of kappa-opioid receptor. Circ Res 1999; 84:1388-1395.

37. Ho JC, WU S, KAm KW et al. Effects of pharmacological preconditioning with $\mathrm{U} 50488 \mathrm{H}$ on calcium homeostasis in rat ventricular myocytes subjected to metabolic inhibition and anoxia. Br J Pharmacol 2002; 137:739-748.

38. Terracciano CM, Macleod KT. Effects of acidosis on $\mathrm{Na}^{+} /$ $\mathrm{Ca}^{2+}$ exchange and consequences for relaxation in guinea pig cardiac myocytes. Am J Physiol 1994; 267:H477-H487.

39. Quinn FR, Currie S, Duncan AM et al. Myocardial infarction causes increased expression but decreased activity of the myocardial $\mathrm{Na}^{+}-\mathrm{Ca}^{2+}$ exchanger in the rabbit. J Physiol 2003; 553:229-242.

40. YU XC, Li HY, WANG HX et al. U50,488H inhibits effects of norepinephrine in rat cardiomyocytes-cross-talk between kappa-opioid and beta-adrenergic receptors. J Mol Cell Cardiol 1998; 30:405-413.

41. SeKi S, MACLEOD KT. Effects of anoxia on intracellular $\mathrm{Ca}^{2+}$ and contraction in isolated guinea pig cardiac myocytes. Am J Physiol 1995; 268:H1045-H1052.

42. BAKer DL, Hashimoto K, Grupp IL et al. Targeted overexpression of the sarcoplasmic reticulum $\mathrm{Ca}^{2+}$-ATPase increases cardiac contractility in transgenic mouse hearts. Circ Res 1998; 83:1205-1214.

43. Loukianov E, JI Y, GRUPP IL et al. Enhanced myocardial contractility and increased $\mathrm{Ca}^{2+}$ transport function in transgenic hearts expressing the fast-twitch skeletal muscle sarcoplasmic reticulum $\mathrm{Ca}^{2+}$-ATPase. Circ Res 1998; 83:889-897.

44. Sallinen P, Manttari S, Leskinen H et al. The effect of myocardial infarction on the synthesis, concentration and receptor expression of endogenous melatonin. J Pineal Res 2007; 42:254-260.
45. Acuna CD, Escames G, Carazo A et al. Melatonin, mitochondrial homeostasis and mitochondrial-related diseases. Curr Top Med Chem 2002; 2:133-151.

46. Poeggeler B, Thuermann S, Dose A et al. Melatonin's unique radical scavenging properties - roles of its functional substituents as revealed by a comparison with its structural analogs. J Pineal Res 2002; 33:20-30.

47. Mahal hS, Sharma HS, Mukherjee T. Antioxidant properties of melatonin: a pulse radiolysis study. Free Radic Biol Med 1999; 26:557-565.

48. Poeggeler B, Reiter RJ, Tan DX et al. Melatonin, hydroxyl radical-mediated oxidative damage, and aging: a hypothesis. J Pineal Res 1993; 14:151-168.

49. Simko F, Paulis L. Melatonin as a potential antihypertensive treatment. J Pineal Res 2007; 42:319-322.

50. Mayo JC, Sainz RM, Antoli I et al. Melatonin regulation of antioxidant enzyme gene expression. Cell Mol Life Sci 2002; 59:1706-1713.

51. Okatani Y, Wakatsuki A, Kaneda C. Melatonin increases activities of glutathione peroxidase and superoxide dismutase in fetal rat brain. J Pineal Res 2000; 28:89-96.

52. Wakatsuki A, OKatani Y, Shinohara K et al. Melatonin protects fetal rat brain against oxidative mitochondrial damage. J Pineal Res 2001; 30:22-28.

53. Okatani Y, Wakatsuki A, Shinohara K et al. Melatonin protects against oxidative mitochondrial damage induced in rat placenta by ischemia and reperfusion. J Pineal Res 2001; 31:173-178.

54. Wakatsuki A, Okatani Y, Shinohara K et al. Melatonin protects against ischemia/reperfusion-induced oxidative damage to mitochondria in fetal rat brain. J Pineal Res 2001; 31:167-172.

55. Leon J, Acuna-Castroviejo D, Escames G et al. Melatonin mitigates mitochondrial malfunction. J Pineal Res 2005; 38:19.

56. Schillaci G, Vaudo G, Pasqualini L et al. Left ventricular mass and systolic dysfunction in essential hypertension. J Hum Hypertens 2002; 16:117-122.

57. Cloward TV, WALKer JM, FARNEY RJ et al. Left ventricular hypertrophy is a common echocardiographic abnormality in severe obstructive sleep apnea and reverses with nasal continuous positive airway pressure. Chest 2003; 124:594-601.

58. Lorell BH, CARABello BA. Left ventricular hypertrophy: pathogenesis, detection, and prognosis. Circulation 2000; 102:470-479.

59. Maclennan DH, Abu-Abed M, Kang C. Structure-function relationships in $\mathrm{Ca}\left(2^{+}\right)$cycling proteins. $\mathrm{J}$ Mol Cell Cardiol 2002; 34:897-918.

60. Chamberlain BK, Volpe P, Fleischer S. Calcium-induced calcium release from purified cardiac sarcoplasmic reticulum vesicles. General characteristics. J Biol Chem 1984; 259:7540 7546.

61. BERS DM. Calcium fluxes involved in control of cardiac myocyte contraction. Circ Res 2000; 87:275-281.

62. Osada M, Netticadan T, TAmura K et al. Modification of ischemia-reperfusion-induced changes in cardiac sarcoplasmic reticulum by preconditioning. Am J Physiol 1998; 274:H2025H2034.

63. Reiken S, Gaburjakova M, Guatimosim S et al. Protein kinase A phosphorylation of the cardiac calcium release channel (ryanodine receptor) in normal and failing hearts. Role of phosphatases and response to isoproterenol. J Biol Chem 2003; 278:444-453. 
64. Birkeland JA, Sejersted OM, Taraldsen T et al. EC-coupling in normal and failing hearts. Scand Cardiovasc J 2005; 39: $13-23$.

65. Gomez AM, Valdivia HH, Cheng H et al. Defective excitation-contraction coupling in experimental cardiac hypertrophy and heart failure. Science 1997; 276:800-806.

66. Pieske B, Maier LS, Bers DM et al. $\mathrm{Ca}^{2+}$ handling and sarcoplasmic reticulum $\mathrm{Ca}^{2+}$ content in isolated failing and nonfailing human myocardium. Circ Res 1999; 85:38-46.
67. Salie R, Harper I, Cillie $\mathrm{C}$ et al. Melatonin protects against ischaemic-reperfusion myocardial damage. J Mol Cell Cardiol 2001; 33:343-357.

68. Tengattini S, Reiter RJ, TAn DX et al. Cardiovascular diseases: protective effects of melatonin. J Pineal Res 2008; 44:16-25. 